\title{
REFLUX PROBLEM ANALYSIS AND STRUCTURE OPTIMIZATION OF THE SPIRAL GROOVED-WHEEL FERTILIZER APPARATUS
}

\author{
Zheng, W.-Q.***; Zhang, L.-P. ${ }^{* * *}$; Zhang, L.-X. ${ }^{* * *} \&$ Zhou, J.-P.*\# \\ ${ }^{*}$ School of Mechanical Engineering, Xinjiang University, Urumqi 830047, China \\ ${ }^{* *}$ State Key Laboratory for Manufacturing Systems Engineering, Xi'an Jiaotong University, \\ Xi' an 710054, China \\ **** College of Mechanical and Electrical Engineering, Shi Hezi University, Shi Hezi 832003, China \\ E-Mail: lyzzyjs2010@163.com ( ${ }^{\#}$ Corresponding author $)$
}

\begin{abstract}
The spiral grooved-wheel fertilizer apparatus has a reflux problem during the fertilization process, it influences the fertilization uniformity. To improve the fertilization performance of the fertilizer apparatus, the reflux phenomenon and mechanism were analysed in this study. The reflux process of fertilizer particles was simulated with a discrete element software. The motion trail and stresses during the reflux process were analysed. A staggered spiral grooved-wheel was proposed, and the key parameters of the staggered spiral grooved-wheel were determined. Furthermore, a comparative study on the fertilization performance of the staggered spiral, spiral, and straight grooved-wheels was conducted through a bench test. The results show that the staggered grooved-wheel does not appear fertilizer reflux when the staggered length is $e_{\max }=L / 6$. Under the same conditions, the staggered spiral grooved-wheel fertilizer apparatus shows the smallest variation rate of fertilization quantity, follows by those of the spiral and straight grooved-wheel fertilizer apparatuses, successively. Therefore, the staggered spiral grooved-wheel fertilizer apparatus shows the best fertilization uniformity under the premise of satisfactory fertilization quantities.

(Received in May 2020, accepted in August 2020. This paper was with the authors 2 months for 1 revision.)
\end{abstract}

Key Words: Staggered Spiral Grooved-Wheel, Reflux Phenomenon, Fertilization Performances, Structural Optimization

\section{INTRODUCTION}

The best solution to the contradiction between fertilizer consumption reduction and grain yield increase is to increase fertilizer utilization and realize accurate fertilization [1-3]. The outer grooved-wheel fertilizer apparatus is the key carrier for realizing accurate variable-rate fertilization [4]. The performance of the fertilizer apparatus determines the accuracy of fertilization. In the straight grooved-wheel fertilizer apparatus, a high fertilizer distribution at the grooved-wheel exists, but the fertilizer distribution at the teeth ridge is relatively low, showing the pulsation of fertilizer flows and influencing the fertilization uniformity [5-8]. A certain angle exists between the teeth ridge and the axis on the spiral grooved-wheel fertilizer apparatus, replacing the straight grooved-wheel with a spiral grooved-wheel decreases the pulsation of fertilizer flows. However, the spiral grooved-wheel has a fertilizer reflux, which causes the repeated interaction between the fertilizer particles and the spiral grooved-wheel. This phenomenon influences the fertilization uniformity to some extent, decreasing the fertilization accuracy accordingly.

On this basis, many academic studies on the influencing factors of the fertilization uniformity of the outer grooved-wheel fertilizer apparatus have been conducted. However, these studies mainly concentrated on improving the fertilization uniformity of the groovedwheel fertilizer apparatus based on the control theory and discrete element methods. The reflux problem in the spiral grooved-wheel has been rarely studied. The control theory method mainly 
increases the fertilization accuracy by using control theory to optimize the parameters of the control system [9-10] and does not solve the fertilization imbalance caused by the fertilizer apparatus' structure. The discrete element method mainly increases the fertilization uniformity by optimizing the parameters (e.g., diameter, effective working length, revolving speed, number of grooves, and helix angle) of the grooved-wheel fertilizer apparatus based on the discrete element method $[4,10,11]$. Nevertheless, few studies concerning the influences of fertilizer reflux in the spiral grooved-wheel on fertilization uniformity have been conducted. Hence, the fertilizer reflux phenomenon and reflux mechanism in the spiral grooved-wheel fertilizer apparatus were investigated by Discrete Element Method [12]. Structural optimization is important for preventing the reflux of fertilizer particles and increasing the fertilization uniformity and mechanical fertilization accuracy of the spiral grooved-wheel fertilizer apparatus.

\section{STATE OF THE ART}

Many experts and scholars have studied the fertilization performance of the outer groovedwheel fertilizer apparatus. They mainly concentrate on the relations between parameters, like the grooved-wheel diameter, the effective working length, the groove shape, the number of grooves, the rotating speed, and the fertilization uniformity. For example, Gurjar et al. [13] studied the fertilization quantity and power demand laws of the spiral and straight groovedwheels under different working lengths, numbers of grooves, revolving speeds, and fertilizer types. However, they did not study the influences of the above parameters on fertilization uniformity. Ozturk et al. [14] performed an experimental study of the influences of the groovedwheel length, the revolving speed, and the groove shape on the flow uniformity of wheat according to the Taguchi optimization technique and discovered the order of the influencing factors in terms of importance. Nevertheless, they did not study the influences of other factors. Crișan and Roș [15] investigated the influences of grooved-wheel direction on the fertilization uniformity of small seeds at constant diameter, number of grooves, and length. When studying conventional parameters, Kara et al. [16] mentioned the influences of the helix angle on the flow, uniformity, and speed of fertilizers, but they did not mention whether the change in the helix angle can cause reflux problems. Alameen et al. [9] developed a variable rate application (VRA) system and improved its accuracy by shortening the response time. According to their test results, the total fertilization error of the VRA system is only $2.6 \%$. Zhu et al. [4] investigated the influences of the straight grooved-wheel's radius, number of grooves, and effective working length and the sectional shape of the groove on the fertilization performance of the fertilizer apparatus by using a discrete element software. Dun et al. [11] discussed the variation laws of the variable coefficient of the outer grooved-wheel fertilizer apparatus' fertilization quantities with chamfering of the fertilization tongue and disclosed the relationship between the chamfering of the fertilization tongue and the arc length of single groove to obtain the best fertilization uniformity. Wang et al. [17] studied the seeding performance of the spiral and straight grooved-wheel sowing apparatuses under two helix angles through a testbed, finding two influencing factors, namely, the revolving speed of the grooved-wheel and the helix angle. However, the seed reflux was not mentioned in this study. Based on the straight groovedwheel sowing apparatus, Liu et al. [18] designed a spiral grooved-wheel sowing apparatus for rice. They investigated the relationship between the helix angle and the sowing uniformity and the influences of the revolving speed and openness of the grooved-wheel on the sowing quantity. Nevertheless, they did not discuss the seed reflux. Some researchers have optimized design of mechanical components, including the fertilizing mixer, tube and fertilizer uniform fertilizing device, through the discrete element software to increase the fertilization uniformity indirectly $[19,20]$. 
The rest of this study is organized as follows. Section 3 analyses the reflux phenomenon and the influencing factors, constructs a kinetic model of reflux fertilizer particles, and discusses the motion trail and stresses of the reflux fertilizer particles. The structure of the spiral grooved-wheel is optimized, and a staggered spiral grooved-wheel is proposed. Furthermore, the key parameters of the staggered spiral grooved-wheel are determined, and its fertilization performance is simulated. Section 4 presents a comparative study of the fertilization performance of the staggered spiral, spiral, and straight grooved-wheel fertilizer apparatuses based on a bench test. Section 5 summarizes the conclusions.

\section{METHODOLOGY}

\subsection{Structure and working principle of spiral grooved-wheel fertilizer apparatus}

The spiral grooved-wheel fertilizer apparatus is mainly composed of an outer grooved-wheel, a fertilizing box, a fertilizing tongue, a fertilizing baffle, and a fertilizing axis. The groovedwheel is one of the structures that influence fertilization performance of the fertilizer apparatus. The structure of the fertilizer apparatus is shown in Fig. 1.

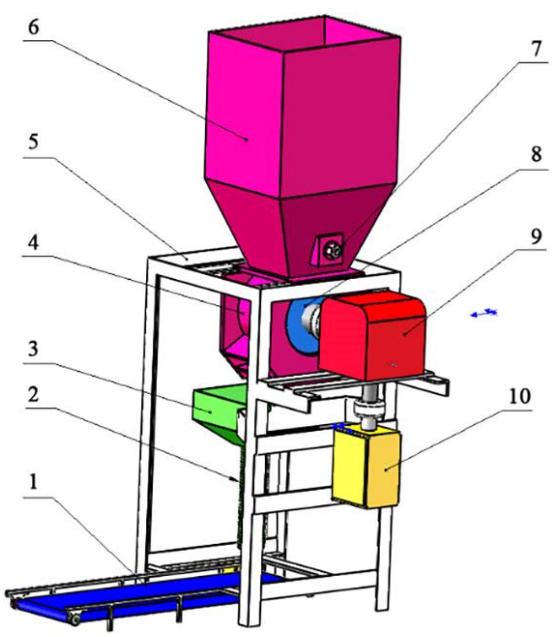

Figure1: Spiral grooved-wheel fertilizer apparatus.
Legend:

1 - Imitated ground conveying mechanism

2 - Fertilizing tube

3 - Fertilizing mixer

4 - Fertilizing chamber

5 - Rack

6 - Fertilizer box

7 - Fertilizer stirring structure

8 - Spiral grooved-wheel

9 - Regulating mechanism

10 - Motor

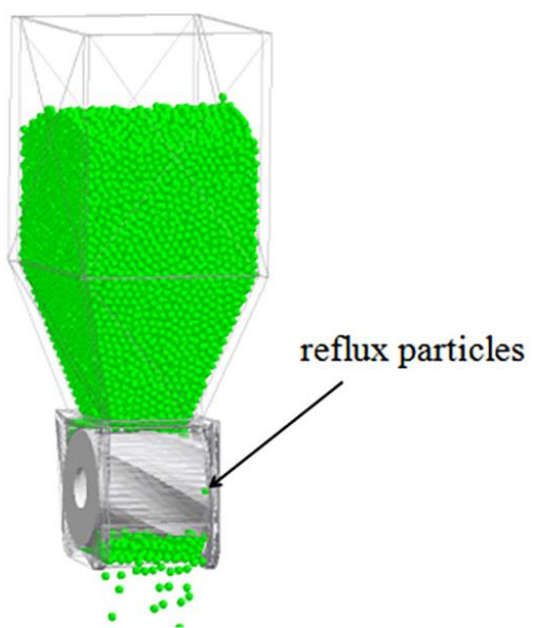

Figure 2: Discrete element simulation model of fertilizer reflux.

The fertilization chamber is beneath the fertilizer box, and fertilizers flow into the fertilizer apparatus through the hole at the bottom of the fertilizer box. When the fertilization axis rotates, the spiral grooved-wheel and the spline baffle ring rotate together, while the fertilizer baffle is fixed. The fertilizing baffle and the spline baffle ring prevent fertilizer flows from two sides of the grooved-wheel. To solve the pulsation flows of fertilizers in the grooved-wheel fertilizer, the straight grooved-wheel is replaced with a spiral grooved-wheel. However, the spiral grooved-wheel fertilizer apparatus exhibits the fertilizer reflux phenomenon in the fertilization process (Fig. 2), and reflux fertilizers pass through the spiral grooved-wheel repeatedly, thus influencing the fertilization performance of the spiral grooved-wheel fertilizer apparatus.

\subsection{Reflux mechanism of spiral grooved-wheel fertilizer apparatus}

Reflux phenomenon influencing factors: The reflux fertilizers pass through the spiral grooved-wheel repeatedly, influencing the fertilization performance of the apparatus to some extent. In order to improve the fertilization uniformity of fertilizer apparatus, the reflux phenomenon and mechanism were discussed, enabling the determination of the influencing factors of fertilizer reflux, which can provide a reference for solving fertilizer reflux and improving the performance of fertilizer apparatus. 
The main influencing factors of fertilizer reflux include the revolving speed of the fertilizer axis and the structure of the spiral grooved-wheel. Changes in the revolving speed of the fertilization axis and the spiral grooved-wheel structure can cause changes in the motion trail and stress of the fertilizer particles, thus generating fertilizer reflux. Hence, the forces of fertilizers in the spiral grooved-wheel fertilizer apparatus must be analysed. By choosing the fertilizer particles in the compulsion layer as the research object, a $\tau$ - $n$ coordinate system was set up along the tangential direction of the teeth ridge $(\tau)$ and the normal line of the teeth ridge $(n)$. In this coordinate system, the forces of the fertilizers in the teeth groove are discussed. The stress analysis is shown in Fig. 3.
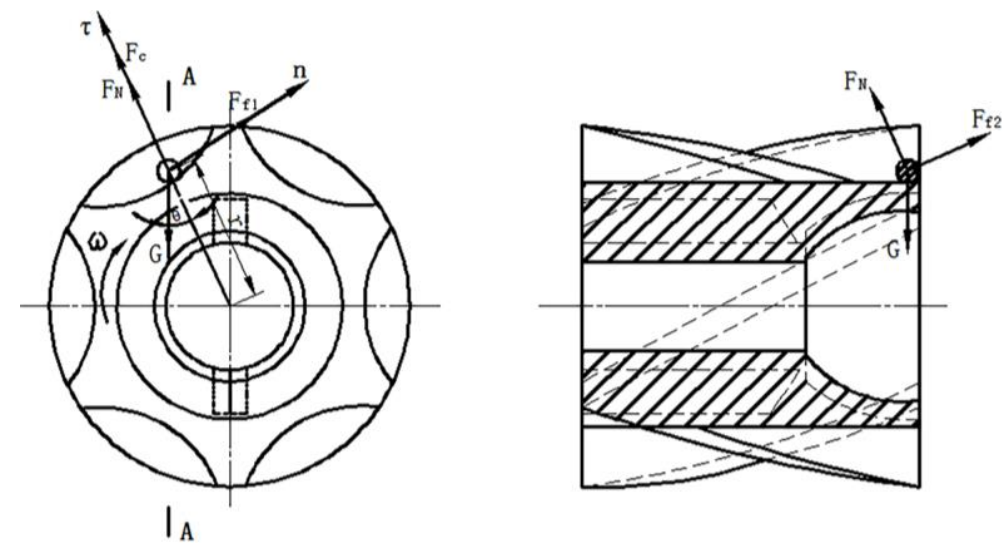

Figure 3: Force analysis of fertilizer particles in the compulsion layer.

Notes: $F_{N}$-extrusion force of the grooved-wheel on the fertilizers $(\mathrm{N}) ; F_{f 1}-$ frictional force between the fertilizers and the grooved-wheel $(\mathrm{N}) ; F_{f 2}$ - frictional force among the fertilizer particles $(\mathrm{N}) ; F_{c}-$ centrifugal force of the fertilizers $(\mathrm{N}) ; G-$ gravity of the fertilizers $(\mathrm{N})$. Considering the stress conditions of single fertilizer particles, at $F_{f 2}=0$, the following can be derived:

$$
\left\{\begin{array}{c}
m a_{n}=F_{f 1}-m g \sin \theta \\
m \omega^{2} r+2 m v_{r}+F_{N}=m g \cos \theta \\
F_{f 1}=F_{N} \tan \varphi \\
v_{r}=\frac{d s_{r}}{d t} \\
a_{n}=\frac{d^{2} s_{r}}{d t^{2}}
\end{array}\right.
$$

where $m$ is the weight per fertilizer particle $(\mathrm{kg}) ; r$ is the distance from the centre of the fertilizer particle to the centre of the grooved-wheel $(\mathrm{m}) ; \omega$ is the angular speed of the grooved-wheel $(\mathrm{rad} / \mathrm{s})$, and $\theta$ is the included angle between the direction of the fertilizers and the horizontal direction $\left(^{\circ}\right) . \varphi$ is the frictional angle between the grooved-wheel and the fertilizer $\left(^{\circ}\right) ; v_{r}$ is the tangential speed of the fertilizers relative to the outer wall of the grooved-wheel $(\mathrm{m} / \mathrm{s}) ; a_{n}$ is the tangential acceleration of the fertilizers along the outer wall of the grooved-wheel $\left(\mathrm{m} / \mathrm{s}^{2}\right)$.

Based on Eq. (1), the following can be derived:

$$
\frac{d s_{r}}{d t}=\frac{\left(g \sin \theta-\omega^{2} r\right) \tan -g \cos \theta}{2 \omega \tan }\left(1-e^{-2 \omega t \tan }\right)
$$

According to Eq. (2), the ultimate filling speed of the fertilizer is:

$$
v_{r}=\frac{d / \cos \lambda-c-(b / 2) \cot \theta}{\sqrt{b / g \sin \theta}}
$$


where $b$ is the thickness of the fertilizers $(\mathrm{mm}) ; d$ is the arc length of the groove $(\mathrm{mm}) ; c$ is the half-width of the fertilizer $(\mathrm{mm}) ; \lambda$ is the helix angle $\left({ }^{\circ}\right)$.

Motion trail of fertilizer particle reflux: Fertilizer particles might generate a reflux when moving in the spiral grooved-wheel. Studying the motion trail in the reflux process and understanding the motion trail can provide references for optimizing the structural parameters and movement parameters of the spiral grooved-wheel. Taking the reflux fertilizer particles for example, the reflux trail of the fertilizers is shown in Fig. 4.

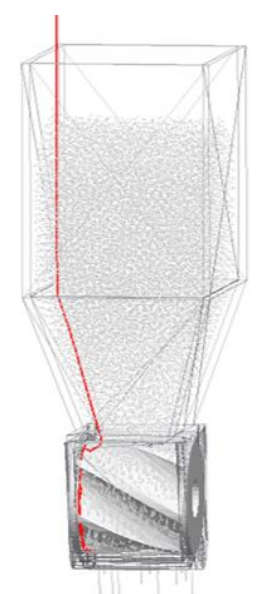

a) Trail before reflux

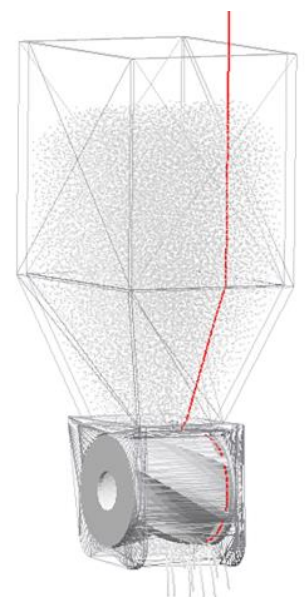

b) Begin to reflow

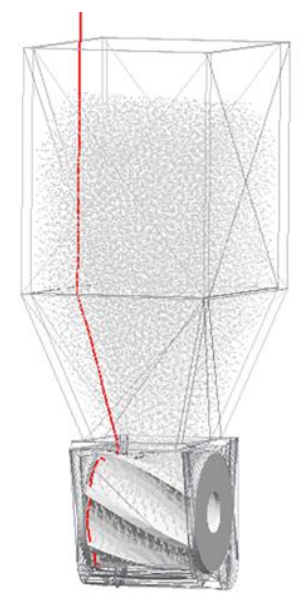

c) Reflux fertilizer rearrange

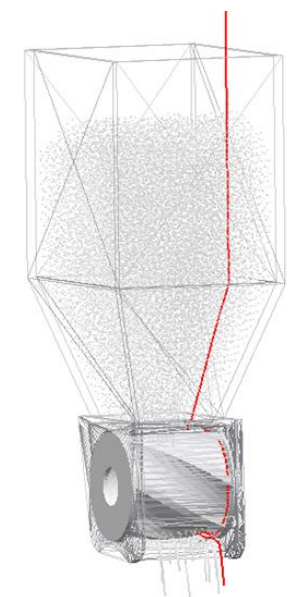

d) Fertilization after reflow

Figure 4: Motion trail of fertilizer particles in the whole reflux process.

In Fig. 4 a, the fertilizer particles enter the fertilizer box and move with the rotation of the spiral grooved-wheel. The red trail is the motion trail of the reflux fertilizer particles before the reflux. The fertilizer particles move along the fertilizer box to the position near the end of the spiral grooved-wheel and then flow toward the outlet of the fertilizer pipe with rotation of the grooved-wheel. In Fig. 4 b, the fertilizer particles cross over the fertilization outlet with the rotation of the grooved-wheel and begin to enter into reflux. They are brought to the inlet along the rotation direction of the grooved-wheel. In Fig. $4 \mathrm{c}$, the reflux particles are carried by the spiral grooved-wheel into the fertilizer pipe again with other fertilizer particles. In Fig. 4 d, the reflux particles are drained along the outlet of the spiral grooved-wheel. These figures represent the entire motion trail of the fertilizer particles from beginning of the reflux to fertilization.

Studies of multiple groups of reflux fertilizer particles indicate that reflux fertilizer particles mainly concentrate near the right end of the spiral grooved-wheel, but no reflux can be observed at the middle and left end of the spiral grooved-wheel. The formation of reflux is related with the forces of the particles in motion. However, the revolving speed and the right structure of the spiral grooved-wheel are the main causes of changes in the force of the reflux particles.

Force analysis of fertilizer particles during reflux: to analyse the forces of the fertilizer particles before and after reflux and the relevant influencing factors, the revolving speed was fixed in the fertilization process during the sampling process, and the fertilizer particles at the left (the $69^{\text {th }}$ particle in the reflux), middle (the $1464^{\text {th }}$ particle), and right (the $899^{\text {th }}$ particle) of the spiral grooved-wheel were collected at any position parallel to the axial direction of the spiral grooved-wheel were selected as the research object. All fertilizer particle samples entered the fertilizer box and began to reflow, taking approximately $5.5 \mathrm{~s}$ to drain. Hence, the research time was set to $6 \mathrm{~s}$. The compressive forces are shown in Fig. 5.

Fig. 5 indicates that the compressive forces on the three fertilizer particles at different fertilization positions in the normal fertilization stage of $0-2.5 \mathrm{~s}$ are $0-0.1 \mathrm{~N}$. At $2.5-4.0 \mathrm{~s}$, the left particle begins to reflow, and the compressive force mainly concentrates within $0.5-1.75 \mathrm{~N}$, with the maximum up to $2.55 \mathrm{~N}$. On contrary, the middle and right particles do not reflow, and 
the compressive forces mainly concentrate within 0.1-0.25 N. At 4.0-5.2 s, only the left particle is in the second fertilization process, and the comprehensive force mainly concentrates within 0-0.6 N. The left particle is fertilized directly without another reflux, indicating that particles might reflow when the compressive force is increased to a certain range.

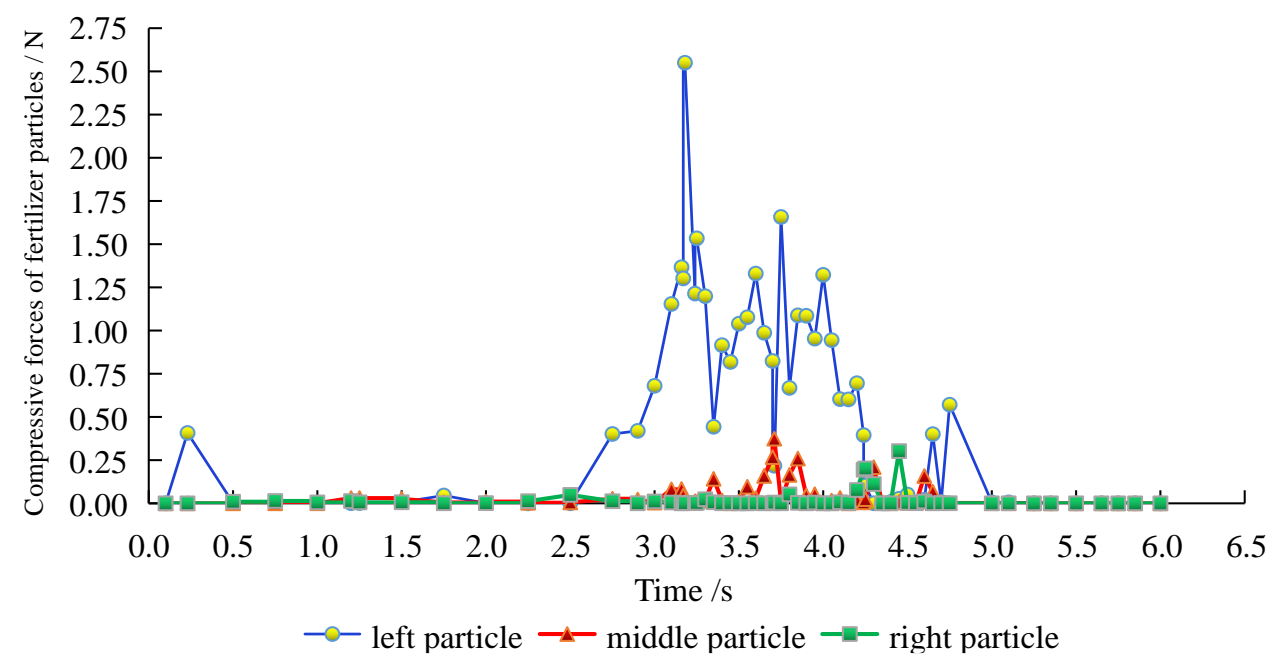

Figure 5: Comparison of compressive forces of fertilizer particles at different positions.

The analysis results indicate that the revolving speed of the fertilization axis and the structure of the spiral grooved-wheel are the two main influencing factors of fertilizer reflux. Optimizing the size and structural parameters of the spiral grooved-wheel fertilizer apparatus, overcoming the spiral grooved-wheel structural defects, and increasing the fertilization uniformity can further improve the fertilization performance of the apparatus.

\subsection{Structural optimization of spiral grooved-wheel}

On the basis of the observation of the multiple reflux particles and the trail analysis and given the same movement parameters, the fertilizer particles on the right end of the spiral groovedwheel within a certain distance to the wall of the fertilization chamber can only reflow when the average compressive force reaches a certain range. Changes in the mean compressive force are mainly related with the structure formed by the teeth ridge and the right wall. To decrease the fertilizer reflux, a new staggered spiral grooved-wheel was designed. The staggered spiral grooved-wheel is formed by the staggered distribution of two spiral grooved-wheels, and the stairs are formed at the hinge of the two spiral grooved-wheels due to zigzag fastening, which change the average compressive force of the fertilizers when they flow through the end of the spiral grooved-wheel, thus decreasing the fertilizer reflux. The structure of the staggered spiral grooved-wheel is shown in Fig. 6.
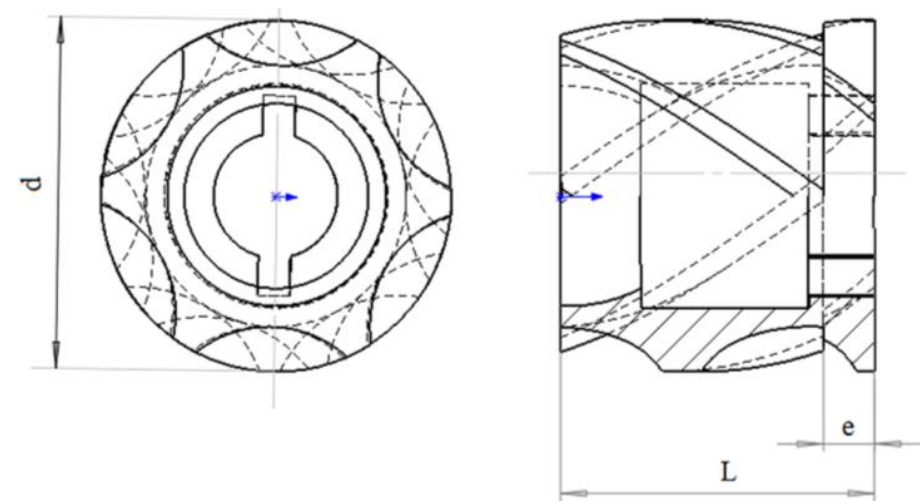

Figure 6: Staggered spiral grooved-wheel. 
Determination of staggered length: The motion trail of the reflux particles in a spiral grooved-wheel with a helix angle of under different revolving speeds within 20-150 r/min was analysed to determine the scope of the regions for the fertilizer particle reflux. Details are shown in Fig. 7.

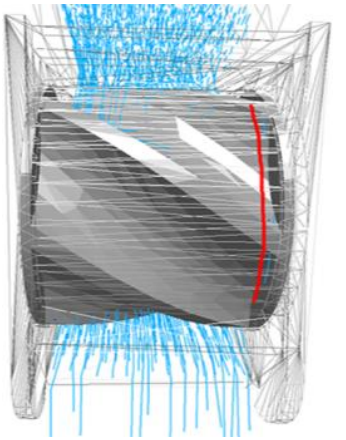

a) $20 \mathrm{r} / \mathrm{min}$

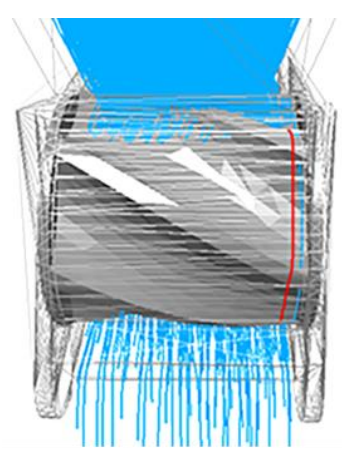

b) $60 \mathrm{r} / \mathrm{min}$

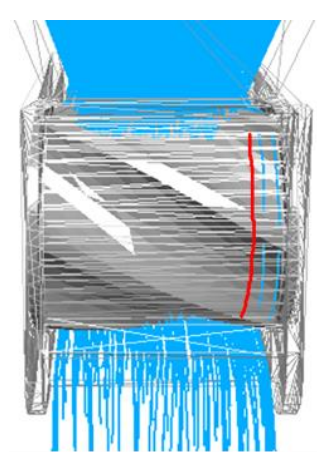

c) $90 \mathrm{r} / \mathrm{min}$

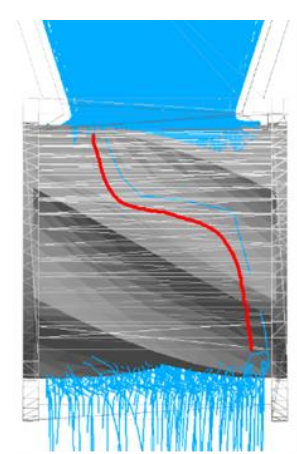

d) $150 \mathrm{r} / \mathrm{min}$

Figure 7: Motion trail of fertilizer particle reflux in the spiral grooved-wheel.

According to the simulation of the fertilization process in the spiral grooved-wheel fertilizer apparatus under different revolving speeds, the working length of the spiral grooved-wheel in this study was set to $L=45 \mathrm{~mm}$. At $20 \mathrm{r} / \mathrm{min}$, intermittent refluxes occurred in the spiral grooved-wheel during the early fertilization stage. The interval among the intermittent refluxes was long. The maximum reflux area was approximately $1 / 20$ of the total working length of the spiral grooved-wheel and near the right wall of the fertilization chamber (Fig. 7 a). At $60 \mathrm{r} / \mathrm{min}$, intermittent refluxes of fertilizer particles occurred, and the reflux area was approximately 1/30 of the working length of the spiral grooved-wheel (Fig. $7 \mathrm{~b}$ ). When the revolving speed increased to $90 \mathrm{r} / \mathrm{min}$, the number of reflux particles increased significantly, and the interval among the intermittent refluxes was short. The maximum reflux area was 1/6 of the working length of the spiral grooved-wheel (Fig. $7 \mathrm{c}$ ). When the revolving speed continued to increase to $150 \mathrm{r} / \mathrm{min}$, the fertilizer particles reflowed upward along the bottom of the spiral groovedwheel (Fig. 7 d). Obviously, the reflux area of fertilizer particles was generally within $0-L / 6$ in the fertilization process. In other words, $e_{\max }=L / 6$. Meanwhile, the reflux of fertilizer particles was more obvious with the increase of the revolving speed of the spiral grooved-wheel, especially after $120 \mathrm{r} / \mathrm{min}$. Therefore, the revolving speed of the fertilizer apparatus must be controlled during the design of structural parameters.

Shape of groove section: To decrease the resistances against the flow of the fertilizer particles and increase the fluidity of fertilizers, the groove section is generally designed as an arch, and the smallest depth of the groove shall be no smaller than half of the fertilizer thickness. Considering the diameter of the groove and the processing technologies, specific data are obtained from Eq. (4). The structure is shown in Fig. 8.
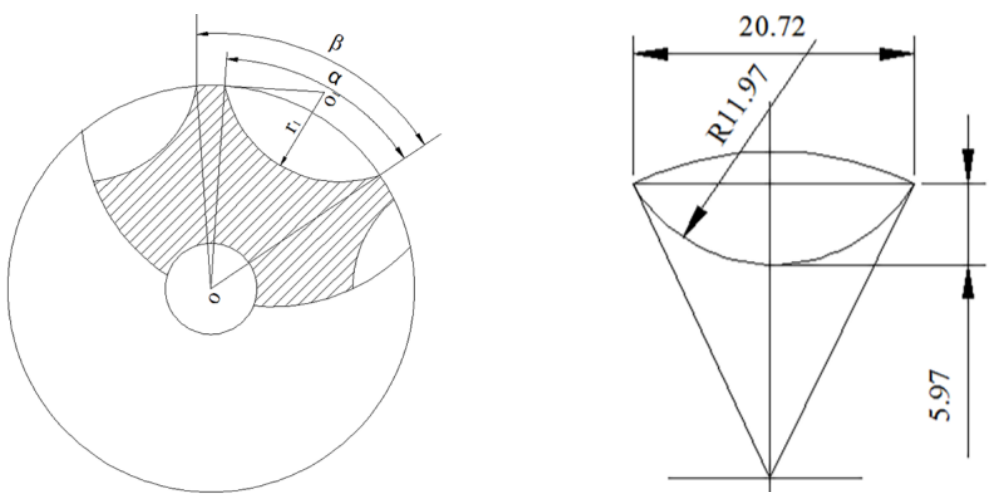

Figure 8: Shape of groove. 


$$
\left\{\begin{array}{c}
\alpha=\frac{2 \pi}{z} \\
\beta=\frac{\alpha(z-1)}{z} \\
r_{1}=R \tan \frac{\alpha}{2} \\
s_{1}=\frac{R^{2}}{2}(\beta-\sin \beta)+\frac{r_{1}^{2}}{2}(\pi-\beta-\sin \beta)
\end{array}\right.
$$

where $\alpha$ is the pitch angle between the adjacent grooves ( $\mathrm{rad}) . \beta$ is the span of the single groove on the grooved-wheel section ( $\mathrm{rad}) . R$ is the radius of the grooved-wheel $(\mathrm{mm}) . r_{1}$ is the radius of the arc groove $(\mathrm{mm})$, and $s_{1}$ is the sectional area of the single arc groove $\left(\mathrm{mm}^{2}\right)$.

\subsection{Fertilization process of staggered spiral grooved wheel}

On the basis of the above design, the staggered spiral grooved-wheel with a diameter of $d=48 \mathrm{~mm}$, an effective working length of $L=45 \mathrm{~mm}$, and a staggered teeth length of $e_{\max }=7.5 \mathrm{~mm}$ was chosen as the research object. The fertilization performance of the staggered spiral grooved-wheel at a revolving speed of 30-150 r/min is discussed (Fig. 9).

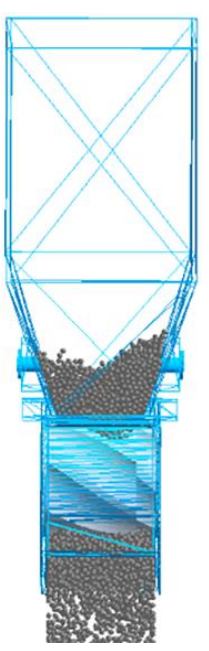

a) $t=1.5 \mathrm{~s}$

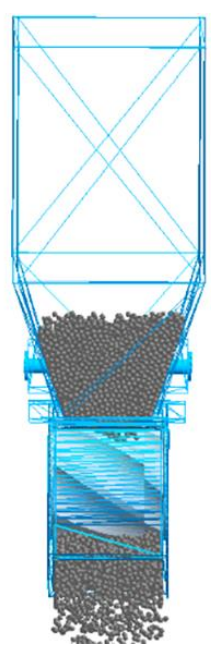

b) $t=2.0 \mathrm{~s}$

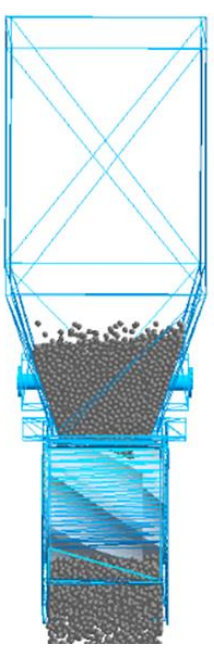

c) $t=2.5 \mathrm{~s}$

Figure 9: Fertilization process of the staggered spiral grooved-wheel (120 r/min).

The entire fertilization process of the staggered grooved-wheel under different revolving speeds was studied, and no fertilizer particle reflux was observed in the entire fertilization process (see Fig. 9).The fertilization quantity in unit time generally increases with the revolving speed, but the fertilization quantity per revolution declines gradually. The results of simulations and modelling indicated [21] that the staggered spiral grooved-wheel can avoid reflux effectively and the fertilization uniformity is more stable.

\section{RESULT ANALYSIS AND DISCUSSIONS}

\subsection{Test conditions}

In the test, the DAP fertilizer, which is widely applied in Xinjiang, was selected. The average geometric diameter and density of DAP are $2.97 \mathrm{~mm}$ and $1.333 \mathrm{~g} / \mathrm{cm}^{3}$, respectively. A total of $10 \mathrm{~kg}$ of fertilizers were used in the test. The self-made fertilization performance test device was used as the testing device, and fertilizers were collected by the static method. The fertilization performance of the three structures of the outer grooved-wheel fertilizer apparatus was compared and analysed. 


\subsection{Test methods and objective}

A static test was carried out according to the test methods regulated by China's National Standards GB/T20346.1-2006 and China Machinery Industrial Standards JB/T7864-2013. In the test, the straight, spiral, and staggered spiral grooved-wheel fertilizer apparatuses were installed on the test apparatus to test the fertilization performance. To measure the fertilization performance of the spiral fertilizer apparatus after optimization, the variation rate of fertilization quantity $(K)$ was applied for measurement. The variation rate of fertilization quantity refers to the ratio of the mean of the absolute value of the differences between the average fertilization quantities of the fertilizer apparatus at any sampling moments and in time $t$ relative to the equivalent average fertilization quantities in the sampling period, Eq. (5). The higher the value of $K$ is, the higher the pulsation and the poorer the fertilization uniformity will be.

$$
K=\frac{\frac{1}{N} \sum_{i=1}^{N}\left|q_{i-} q_{a v}\right|}{q_{n}} \times 100 \%
$$

where $q_{i}$ is the fertilization quantity at any moment in the sampling period $(\mathrm{g}) . q_{a v}$ is the average fertilization quantity in the sampling period $(\mathrm{g}) . q_{n}$ is the equivalent average fertilization quantity in the sampling time $(\mathrm{g})$.

When the apparatus has a stable fertilization performance, the sampling period is determined by the revolving speed of the apparatus at measurement. A total of 5-6 measurements were performed within the revolving speed range of $30-150 \mathrm{r} / \mathrm{min}$, and the mean was selected. The total time was $6 \mathrm{~s}$.

\subsection{Test schemes and results analysis}

The fertilization quantities of the straight, spiral, and staggered spiral grooved-wheels within $30-150 \mathrm{r} / \mathrm{min}$ were measured. To ensure the accuracy of the measurement results, data were collected within 1.5-5.5 s. The test data analysis is listed in Fig. 10.

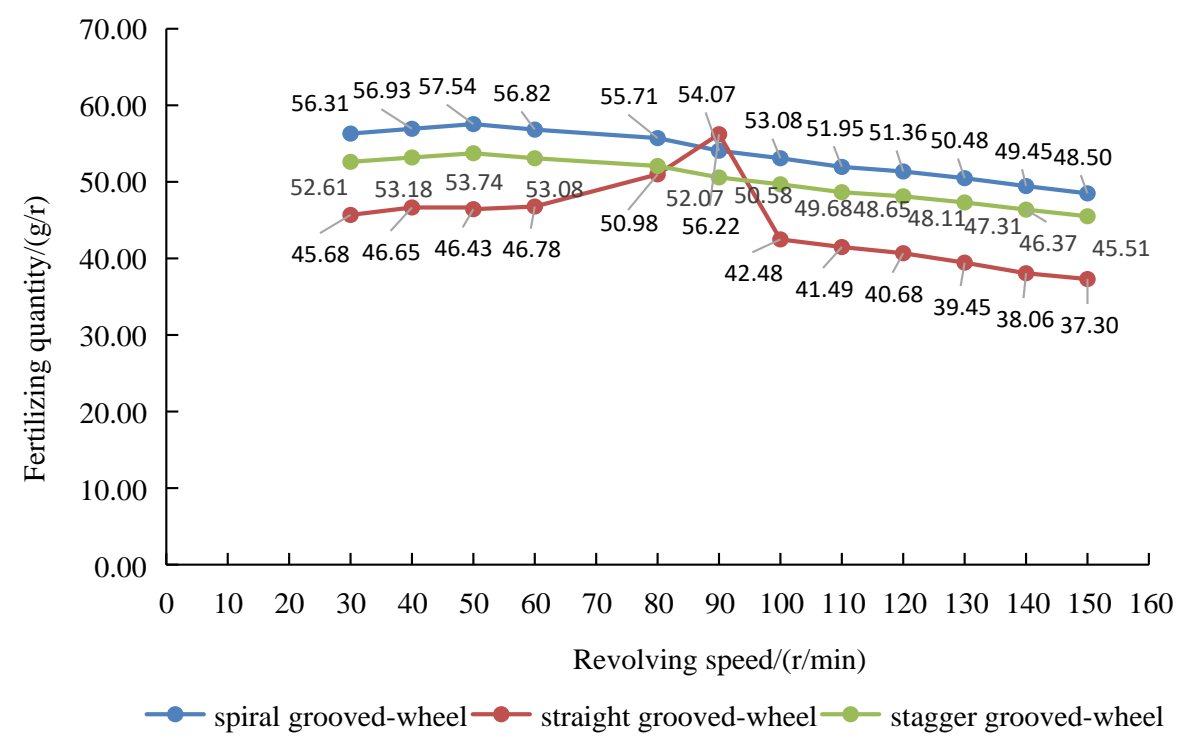

Figure 10: Comparison of fertilization quantities of three grooved-wheels.

Fig. 10 shows that the fertilization quantity per revolution of the three grooved-wheels decreased continuously with the increase of the revolving speed. For the straight grooved-wheel, the average fertilization quantity is $44.35 \mathrm{~g} / \mathrm{r}$. However, the fertilization quantity at $90 \mathrm{r} / \mathrm{min}$ increased first and then decreased, mainly because the fertilizer filling coefficient in the grooved-wheel increased continuously with the revolving speed and reached the peak at 
$90 \mathrm{r} / \mathrm{min}$. Later, the filling coefficient decreased continuously with the continuous increase of the revolving speed, and the fertilization quantity per revolution declined accordingly. With the increase of the revolving speed, average fertilization quantity of the spiral grooved-wheel fertilizer apparatus is $53.52 \mathrm{~g} / \mathrm{r}$. However, the fertilization quantity per revolution is still higher than that of the straight grooved-wheel. With the increase of the revolving speed, the average fertilization quantity of the staggered spiral grooved-wheel fertilizer apparatus is $50.08 \mathrm{~g} / \mathrm{r}$. The variation trend is similar with that of the spiral grooved-wheel fertilizer apparatus, and the fertilization quantity per revolution is slightly lower than that of the spiral grooved-wheel fertilizer apparatus and higher than that of the straight grooved-wheel fertilizer apparatus.

According to Eq. (5), the variation rates of fertilization quantity under other revolving speed can be calculated from the statistics of the test data. Details are shown in Table I.

Table I: Variation rates of fertilization quantity of three grooved-wheels.

\begin{tabular}{|c|c|c|c|c|c|c|c|c|c|c|c|c|}
\hline $\begin{array}{c}\text { Revolving } \\
\text { speed }\end{array}$ & 30 & 40 & 50 & 70 & 80 & 90 & 100 & 110 & 120 & 130 & 140 & 150 \\
\hline $\begin{array}{c}\text { Spiral } \\
\text { grooved- } \\
\text { wheel }\end{array}$ & $12.28 \%$ & $11.73 \%$ & $11.72 \%$ & $7.22 \%$ & $4.87 \%$ & $5.67 \%$ & $4.47 \%$ & $4.83 \%$ & $3.19 \%$ & $3.54 \%$ & $3.30 \%$ & $3.13 \%$ \\
\hline $\begin{array}{l}\text { Stagger } \\
\text { spiral } \\
\text { grooved- } \\
\text { wheel }\end{array}$ & $6.20 \%$ & $6.37 \%$ & $7.59 \%$ & $3.75 \%$ & $3.04 \%$ & $3.69 \%$ & $2.80 \%$ & $3.16 \%$ & $1.90 \%$ & $2.11 \%$ & $1.927 \%$ & $1.843 \%$ \\
\hline $\begin{array}{c}\text { Straight } \\
\text { grooved- } \\
\text { wheel }\end{array}$ & $22.5 \%$ & $16.8 \%$ & $13.8 \%$ & $8.88 \%$ & $6.55 \%$ & $6.65 \%$ & $5.89 \%$ & $5.03 \%$ & $4.98 \%$ & $5.17 \%$ & $4.82 \%$ & $4.37 \%$ \\
\hline
\end{tabular}

In Table I, with increase of the revolving speed from $30 \mathrm{r} / \mathrm{min}$ to $150 \mathrm{r} / \mathrm{min}$, the variation rate of the fertilization quantity of the staggered spiral grooved-wheel decreased from $6.2 \%$ to $1.843 \%$. The variation rate of the fertilization quantity of the spiral grooved-wheel decreased from $12.28 \%$ to $3.13 \%$, and that of the straight grooved-wheel decreased from $22.52 \%$ to $4.371 \%$. The variation rates of the fertilization quantity of the three grooved-wheels shows a decreasing trend with the increase of speed. The staggered spiral grooved-wheel exhibited the smallest variation rate of fertilization quantity, followed by the spiral and straight groovedwheels, successively.

\section{CONCLUSION}

To solve the fertilizer reflux phenomenon and increase the fertilization uniformity of the spiral grooved-wheel fertilizer apparatus during the fertilization process, the fertilizer particle reflux mechanism in the spiral grooved-wheel was studied by a discrete element software and the structure of the spiral grooved-wheel was optimized. A staggered spiral grooved-wheel is proposed and key parameters were determined. A comparative analysis of the straight, staggered spiral, and spiral grooved-wheel fertilizer apparatuses was carried out by using a test device. Some major conclusions could be drawn.

(1) Under the same conditions, the spiral grooved-wheel fertilizer apparatus shows the highest fertilization quantity under different revolving speeds, followed by the staggered spiral and straight grooved-wheel fertilizer apparatuses, successively. According to the range of fertilization quantity demanded of a fertilizer machinery, the fertilization performance of the straight grooved-wheel fertilizer apparatus is lower than this range under low speed and can easily lead to inadequate fertilization. The fertilization quantity of the spiral grooved-wheel fertilizer apparatus is higher than this range and can easily cause excessive fertilization. The 
fertilization quantity of the staggered spiral grooved-wheel fertilizer apparatus is within this range, meeting the quality demands of fertilizing machinery.

(2) The variation rates of the fertilization quantity of the three grooved-wheels decreases gradually with the increase in revolving speed. The variation rate of the fertilization quantity of the staggered spiral grooved-wheel is the lowest, followed by those of the spiral and straight grooved-wheels, successively. The difference is extremely obvious under low revolving speed. The staggered spiral grooved-wheel fertilizer apparatus has the smallest variation rate of fertilization quantity, without fertilizer reflux in the fertilization process. The staggered spiral grooved-wheel fertilizer apparatus solves the fertilizer reflux problem of the spiral groovedwheel fertilizer apparatus in the fertilization process to some extent.

These research conclusions can increase the fertilization uniformity of the grooved-wheel fertilizer apparatus effectively and provide references for studying the machinery structure to increase the fertilization uniformity and accuracy. Future studies will perform a fertilization experiment using the staggered spiral grooved-wheel fertilizer apparatus in the field and improve the apparatus continuously to promote the apparatus.

\section{ACKNOWLEDGEMENT}

The study was supported by Xinjiang Uygur Autonomous Region Natural Science Foundation (No. 2019D01C029) and Xi'an Jiaotong University State key laboratory for manufacturing systems engineering open Project Research Fund (No. sklms2019012).

\section{REFERENCES}

[1] Pallottino, F.; Antonucci, F.; Costa, C.; Bisaglia, C.; Figorilli, S.; Menesatti, P. (2019). Optoelectronic proximal sensing vehicle-mounted technologies in precision agriculture: A review, Computers and Electronics in Agriculture, Vol. 162, 859-873, doi:10.1016/j.compag.2019.05.034

[2] Zhang, W.; Cao, G.; Li, X.; Zhang, H.; Wang, C.; Liu, Q.; Chen, X.; Cui, Z.; Shen, J.; Jiang, R.; Mi, G.; Miao, Y.; Zhang, F.; Dou, Z. (2016). Closing yield gaps in China by empowering smallholder farmers, Nature, Vol. 537, No. 7622, 671-674, doi:10.1038/nature19368

[3] Petrović, D.; Jurišić, M.; Tadić, V.; Plaščak, I.; Barač, Ž. (2018). Different sensor systems for the application of variable rate technology in permanent crops, Tehnicki glasnik - Technical Journal, Vol. 12, No. 3, 188-195, doi:10.31803/tg-20180213125928

[4] Zhu, Q.; Wu, G.; Chen, L.; Zhao, C.; Meng, Z. (2018). Influences of structure parameters of straight flute wheel on quantities of fertilizer apparatus, Transactions of the Chinese Society of Agricultural Engineering, Vol. 34, No. 18, 12-20, doi:10.11975/j.issn.1002-6819.2018.18.002

[5] Shi, Y.; Chen, M.; Wang, X.; Odhiambo, M. O.; Zhang, Y.; Ding, W. (2017). Analysis and experiment of fertilizing performance for precision fertilizer applicator in rice and wheat fields, Transaction of the Chinese Society for Agricultural Machinery, Vol. 48, No. 7, 97-103, doi:10.6041/j.issn.1000-1298.2017.07.012

[6] Zhang, L.; Zhang, L.; Zheng, W. (2018). Fertilizer feeding mechanism and experimental study of a spiral grooved-wheel fertilizer feeder, Journal of Engineering Science and Technology Review, Vol. 11, No. 6, 107-115, doi:10.25103/jestr.116.14

[7] He, L.; Zhao, M.; Zhao, T.; Hao, X.; Zhang, X.; He, R. (2019). Design and experimental of the spiral trough seed metering for rice and wheat, Journal of Hunan Agricultural University (Natural Science Edition), Vol. 45, No. 6, 657-663, doi:10.13331/j.cnki.jhau.2019.06.015

[8] Yang, Z.; Zhu, Q.; Sun, J.; Chen, Z.; Zhang, Z. (2018). Study on the performance of fluted roller fertilizer distributor based on EDEM and 3D printing, Journal of Agricultural Mechanization Research, Vol. 40, No. 5, 175-180, doi:10.3969/j.issn.1003-188X.2018.05.032

[9] Alameen, A. A.; Al-Gaadi, K. A.; Tola, E. (2019). Development and performance evaluation of a control system for variable rate granular fertilizer application, Computers and Electronics in Agriculture, Vol. 160, 31-39, doi:10.1016/j.compag.2019.03.011 
[10] Otake, T.; Shindo, H.; Saito, M.; Honjo, M.; Katahira, M.; Natsuga, M. (2019). Drill-fertilizing cultivation effects on Welsh onion root growth and primary growth, Journal of the Japanese Society of Agricultural Machinery and Food Engineers, Vol. 81, No. 5, 317-324

[11] Dun, G.; Yu, C.; Yang, Y.; Chen, H.; Ji, W.; Ye, J. (2018). Discharging characteristic test of outergroove wheel fertilizer and parameter optimization of fertilizer tongue by discrete element simulation, Journal of Human Agricultural University (Natural Science Edition), Vol. 44, No. 6, 661-665, doi:10.13331/j.cnki.jhau.2018.06.015

[12] Gao, K. D.; Xu, W. B.; Zhang, X.; Wang, G. (2018). Analysis of spiral aggregate device on the sump cleaning machine by discrete element method, International Journal of Simulation Modelling, Vol. 17, No. 4, 643-656, doi:10.2507/IJSIMM17(4)453

[13] Gurjar, B.; Sahoo, P. K.; Kumar, A. (2017). Design and development of variable rate metering system for fertilizer application, Journal of Agricultural Engineering, Vol. 54, No. 3, 12-21

[14] Ozturk, I.; Yildirim, Y.; Hinislioglu, S.; Demir, B.; Kus, E. (2012). Optimization of seed flow evenness of fluted rolls used in seed drills by Taguchi method, Scientific Research and Essays, Vol. 7, No. 1, 78-85, Paper F2ACBE826739, doi:10.5897/SRE11.1445

[15] Crișan, V. D.; Roș, V. (2012). Comparative analysis of distribution uniformity on plain and inclined fluted rollers, Bulletin UASVM Agriculture, Vol. 69, No. 1, 157-162

[16] Kara, M.; Bayhan, A. K.; Ozsert, I.; Yildirim, Y. (2010). Performance of fluted roll metering devices in seed drills with ammonium sulphate and diammonium phosphate, Applied Engineering in Agriculture, Vol. 26, No. 2, 197-201, doi:10.13031/2013.29537

[17] Wang, Y.; Yang, W.; Wang, X. (2006). Study on row sowing device with spiral grooved-wheel, Journal of Xinjiang Agricultural University, Vol. 29, No. 1, 67-70, doi:10.3969/j.issn.1007$\underline{8614.2006 .01 .017}$

[18] Liu, C.; Zang, Y.; Luo, X.; Zeng, S.; Wang, Z.; Yang, W.; Zheng, L. (2016). Design and experiment of spiral grooved wheel for rice direct seeding machine, Journal of Shenyang Agricultural University, Vol. 47, No. 6, 734-739, doi:10.3969/j.issn.1000-1700.2016.06.015

[19] Dun, G.; Chen, H.; Feng, Y.; Yang, J.; Li, A.; Zha, S. (2016). Parameter optimization and test of key parts of fertilizer allocation device based on EDEM software, Transactions of the Chinese Society of Agricultural Engineering, Vol. 32, No. 7, 36-42, doi:10.11975/j.issn.1002$\underline{6819.2016 .07 .005}$

[20] Yuan, J.; Xin, Z.; Niu, Z.; Li, Y.; Liu, X.; Xin, S.; Wang, J.; Wang, L. (2019). Discrete element model simulation and verification of fertilizer blending uniformity of variable rate fertilization based on relevance vector machine, Transactions of the Chinese Society of Agricultural Engineering, Vol. 35, No. 8, 37-45, doi:10.11975/j.issn.1002-6819.2019.08.005

[21] Matejic, M.; Tadic, B.; Lazarevic, M.; Misic, M.; Vukelic, D. (2018). Modelling and simulation of a novel modular fixture for a flexible manufacturing system, International Journal of Simulation Modelling, Vol. 17, No. 1, 18-29, doi:10.2507/IJSIMM17(1)407 